\title{
Distribuição da cota-parte do ICMS: como pode ser utilizada para promover melhores resultados na educação?
}

\author{
Maiara Sasso' \\ Patrícia Siqueira Varelal (D) \\ Patricia Righetto' (D)
}

\section{RESUMO}

Este estudo visa responder aos seguintes questionamentos: quais diretrizes devem ser observadas no desenho da transferência da parcela discricionária da cota-parte do Imposto sobre Operações relativas à Circulação de Mercadorias e sobre Prestações de Serviços de Transporte Interestadual e Intermunicipal e de Comunicação (ICMS) pelos estados aos municípios para se ter melhorias nos resultados da educação? Quais estados possuem leis mais favoráveis a essa mudança legislativa? Os achados indicam que há diretrizes que dependem das leis formuladas - autonomia, equidade, incentivo, simplicidade, focalização e salvaguarda dos objetivos do transferidor - e outras que devem ser compreendidas em um contexto mais amplo em que as leis estaduais se inserem. Assim, é indispensável analisar as particularidades de cada ente para o desenho de transferências que viabilize o alcance dos resultados desejados e não fomente comportamentos indesejados.

PALAVRAS-CHAVE

regime de colaboração; transferências intergovernamentais; cota-parte do ICMS.

Universidade de São Paulo, São Paulo, SP, Brasil. 


\title{
DISTRIBUTION OF THE ICMS SHARE: HOW CAN IT BE USED TO PROMOTE BETTER RESULTS IN EDUCATION?
}

\begin{abstract}
This paper aims to answer the following question: which guidelines should be observed when designing the transfer of discretionary ICMS share by states to municipalities in order to improve educational results, and which states have laws more favorable to this legislative change? The findings indicate that some guidelines depend on formulated laws (autonomy, equity, incentive, simplicity, singular focus, and safeguarding of grantor's objectives), and others must be understood in a broader context involving state laws. Thus, the particularities of each entity must be analyzed so the design of transfers can achieve the desired results and not encourage unwanted behaviors.
\end{abstract}

\section{KEYWORDS}

collaborative regime; intergovernmental transfers; ICMS share.

\section{DISTRIBUCIÓN DE LA CUOTA DEL ICMS: ¿CÓMO SE PUEDE UTILIZAR PARA PROMOVER MEJORES RESULTADOS EN EDUCACIÓN?}

\section{RESUMEN}

Este artículo tiene como objetivo responder a la siguiente pregunta: ¿qué pautas deben observarse en el diseño de la transferencia de la cuota del ICMS por parte de los estados a las municipalidades para mejorar los resultados de la educación y qué estados tienen leyes más favorables a este cambio? Los resultados indican que existen pautas que dependen de las leyes formuladas (autonomía, equidad, incentivo, simplicidad, enfoque singular y salvaguarda de los objetivos del otorgante) y otras que deben entenderse en un contexto más amplio en el que se encuentran las leyes estatales. Por lo tanto, es esencial analizar las particularidades de cada entidad para el diseño de transferencias que permita alcanzar los resultados deseados y no fomente comportamientos no deseados.

PALABRAS CLAVE

régimen de colaboración; transferencias intergubernamentales; cuota de ICMS. 


\section{INTRODUÇÃO}

A Lei no 14.023 do estado do Ceará (Brasil, 2007) usa critérios de distribuição da parcela discricionária da cota-parte do Imposto sobre Operações relativas à Circulação de Mercadorias e sobre Prestações de Serviços de Transporte Interestadual e Intermunicipal e de Comunicação (ICMS) pautados em condicionalidades baseadas em outputs. Nesse tipo de transferência, os resultados alcançados, por meio do serviço prestado e objeto da condicionalidade, são empregados para a apuração dos valores a serem transferidos. No Ceará, o Índice de Qualidade da Educação (IQE) é um dos critérios adotados, e a sua utilização ocasionou melhorias significativas nos índices educacionais do estado (Abrucio, Seggatto e Pereira, 2016).

Considerando tal achado, bem como os de outras pesquisas (Lima, 2012; Brandão, 2014; Barroso, 2015; Carneiro e Irffi, 2017), dois questionamentos surgem: quais diretrizes devem ser observadas no desenho da transferência da parcela discricionária da cota-parte do ICMS pelos estados aos municípios para se ter melhorias nos resultados da educação e quais estados possuem leis mais favoráveis a essa mudança legislativa? O presente estudo visa responder a essas perguntas.

As transferências efetuadas entre entes de níveis distintos são denominadas intergovernamentais. Elas são empregadas como uma maneira de direcionar a lacuna que existe entre receitas e despesas dos entes públicos originada pela diferença na proporção das distribuições das competências tributárias e das responsabilidades de gastos. Em relação às competências tributárias, verifica-se que é reduzida a quantidade de tributos que podem ser arrecadados de modo eficiente por governos municipais, uma vez que critérios tais como a facilidade de se exportar o tributo, a mobilidade da base tributária e a economia de escala na administração do tributo são mais bem observados por governos estaduais e, principalmente, pelo federal. A não observância de uma adequada competência de arrecadação pode estimular, por exemplo, guerras fiscais (Mendes, 2004). Já no que se refere às responsabilidades de gastos, a premissa utilizada corresponde a: "Cada bem público deve ser provido pelo nível de governo que represente de forma mais próxima a área geográfica que se beneficia daquele bem" (Mendes, 2004, p. 432).

O ICMS - principal imposto, em termos de valores, arrecadado pelos estados brasileiros - é um imposto cujo montante é parcialmente transferido aos municípios do respectivo estado em que se deu a arrecadação. A Constituição Federal de 1988 (Brasil, 1988) estabelece que $25 \%$ do ICMS arrecadado deve ser repassado aos municípios do respectivo estado. Desse valor resultante, no mínimo três quartos, ou $75 \%$, deve ser repassado por meio do princípio da derivação, em que parte do imposto é distribuído de acordo com o local em que ocorreu o fato gerador. Esse critério é conhecido também como valor adicionado fiscal (VAF). A ideia que fundamenta tal critério é que os municípios dos quais se obtém a maior parte da arrecadação do ICMS devem ser contemplados com uma parte igualmente superior no momento da transferência.

Sendo o ICMS um imposto incidente sobre a circulação de mercadorias e serviços, municípios mais populosos tendem a arrecadar montantes maiores quando comparados a municípios menos populosos. O restante da parcela que pertence aos municípios - isto é, até um quarto, ou $25 \%$ - deve ser repassado de acordo com leis 
estaduais. Ou seja, há discricionariedade para a distribuição dessa parcela. É a esse restante da parcela que o presente estudo se refere ao utilizar a expressão parcela discricionária da cota-parte do ICMS, ou simplesmente parcela discricionária, uma vez que governos estaduais podem alterar suas leis com o intuito de incentivar o desempenho municipal em determinadas áreas com base nos critérios estabelecidos para a distribuição dessa parcela, como ocorre no Ceará.

Estudos anteriores abordaram a parcela discricionária (Albuquerque, 2009; Sales, 2011; Lima, 2012; Nogueira, 2012; Petterini e Irffi, 2013; Brandão, 2014; Franca, 2014; Barroso, 2015; Garcia, Simonassi e Costa, 2015; Carneiro e Irffi, 2017), no entanto a maioria dessas pesquisas possui como foco principal a identificação do impacto da alteração dos critérios de distribuição dessa parcela sobre os resultados educacionais, e não foi possível localizar estudos que tratam das diretrizes que devem ser consideradas para a determinação desses critérios, ou desenho da transferência, para que os resultados educacionais sejam de fato alcançados.

A relevância deste trabalho dá-se ao se levar em conta que os resultados educacionais almejados podem depender, entre outros fatores, dos aspectos abordados no desenho da transferência. No caso da parcela discricionária da cota-parte do ICMS, há diretrizes que não devem ser desconsideradas para o desenho das transferências; algumas delas dependem fortemente de leis estaduais, enquanto outras estão compreendidas em um contexto mais amplo do que as próprias leis dos estados específicas sobre o tema. Entende-se que as diretrizes discriminadas neste estudo não compreendem uma lista exaustiva de aspectos a serem discutidos para o alcance dos resultados. Todavia, a sua não observância pode provocar ineficiência na transferência da parcela discricionária.

Adicionalmente, é importante destacar a relevância do desenho adequado da transferência intergovernamental, uma vez que, a longo prazo, pode fomentar comportamentos não desejados, como a dependência municipal por transferência, sem, contudo, se ter uma busca por melhores práticas e/ou resultados. A título de exemplo se tem o Fundo de Participação dos Municípios (FPM), em que o desenho da transferência garante valores superiores a municípios menos populosos, sem demandar melhorias nas práticas e/ou resultados, o que, em vários casos, fomenta a prática de renúncia fiscal de tributos de competência municipal com vistas a evitar desaprovação do político eleito.

\section{REFERENCIAL TEÓRICO}

\section{TRANSFERÊNCIAS INTERGOVERNAMENTAIS}

As transferências intergovernamentais referem-se aos recursos repassados entre diferentes níveis de governo - federal para estadual e estadual para municipal. Um dos motivos para a existência dessas transferências é o desequilíbrio entre a descentralização da execução das políticas públicas e a arrecadação dos tributos pelos diferentes níveis de governo. Assim, as transferências intergovernamentais são um mecanismo utilizado para reduzir esse desequilíbrio e redistribuir recursos entre regiões com níveis distintos de renda e de desenvolvimento (Mendes, 2004). 
De acordo com Shah (2007), as transferências intergovernamentais podem ser usadas também como um mecanismo para influenciar as prioridades locais, lidar com infraestruturas deficitárias e criar estabilidade macroeconômica em regiões carentes, estabelecer padrões nacionais mínimos e compensar externalidades ou spillovers — ações públicas promovidas por um governo local que, além de beneficiar os membros da localidade, geram benefícios a membros de outras regiões, isto é, sob a responsabilidade de outros governos.

As transferências intergovernamentais podem ser classificadas como transferência de propósito geral ou incondicional e de propósito específico ou condicional (Shah, 2007). A primeira consiste em um suporte orçamentário geral em que os repasses são realizados sem restrições atreladas a eles. Isto é, correspondem a transferências previstas em lei e feitas com o intuito de preservar a autonomia dos entes, principalmente os locais e, dessa maneira, promover a equidade interjurisdicional. Esse tipo de transferência, em geral, provoca somente efeito de aumento de renda, e, como não são impostas restrições, os receptores possuem discricionariedade para a alocação dos recursos (Shah, 2007).

Já as transferências de propósito específico ou condicional objetivam, sobretudo, fornecer incentivos para que os governos invistam em programas ou atividades específicas. Essas transferências, com frequência, são realizadas especificando-se em quais despesas os recursos podem ser utilizados (condicionalidade baseada em input), podendo configurar-se como intrusivas e improdutivas, ou quais resultados devem ser obtidos por meio do serviço prestado com os recursos transferidos (condicionalidade baseada em output), o que pode, além de preservar a autonomia dos governos locais, favorecer os objetivos dos concessores ou transferidores (Shah, 2007). O Quadro 1 apresenta características desses dois tipos de condicionalidade.

Quadro 1- Condicionalidades baseadas em input e output.

\begin{tabular}{|l|c|c|}
\hline \multirow{2}{*}{ Característica } & \multicolumn{2}{|c|}{ Condicionalidade } \\
\cline { 2 - 3 } & Input & Output \\
\hline Principal objetivo & Níveis de gastos & $\begin{array}{c}\text { Qualidade dos serviços } \\
\text { públicos e acesso a eles }\end{array}$ \\
\hline $\begin{array}{l}\text { Design da concessão } \\
\text { e administração }\end{array}$ & Complexo & Simples e transparente \\
\hline Condições & $\begin{array}{c}\text { Despesas em funções } \\
\text { e objetos autorizados }\end{array}$ & $\begin{array}{c}\text { Resulta da prestação } \\
\text { de serviço/output }\end{array}$ \\
\hline $\begin{array}{l}\text { Autonomia do governo local } \\
\text { e flexibilidade orçamentária }\end{array}$ & Pouca & Absoluta \\
\hline Transparência & Pouca & Absoluta \\
\hline Foco & Interno & $\begin{array}{c}\text { Externo, competição, } \\
\text { inovação e benchmarking }\end{array}$ \\
\hline Accountability & $\begin{array}{c}\text { Controle baseado em insumos } \\
\text { e processos com pouca } \\
\text { ou nenhuma preocupação } \\
\text { em resultados }\end{array}$ & Controle baseado em resultados \\
\hline
\end{tabular}

Fonte: adaptado de Shah (2007, p. 14). 
As transferências condicionais podem ser classificadas em sem ou com contrapartida. Segundo Shah (2007), as primeiras são usadas para subsidiar ações consideradas de alta prioridade para as esferas mais altas de governo, porém de baixa prioridade para os governos locais. Já as transferências condicionais com contrapartida demandam que os recursos recebidos sejam destinados a propósitos específicos e requerem que determinada proporção das despesas seja custeada por meio dos recursos dos próprios governos recebedores (Shah, 2007). Além disso, a necessidade de contrapartida estimula maior escrutínio e propriedade local das despesas custeadas por meio das transferências, no entanto, para as jurisdições recebedoras com capacidade fiscal limitada, as transferências com contrapartida podem se configurar com maior peso. Portanto, é desejável que a determinação do percentual de contrapartida seja proporcionalmente inversa à capacidade fiscal per capita da jurisdição.

A transferência condicional com contrapartida pode ser classificada, por sua vez, em limitada ou ilimitada. A limitada é aquela em que o doador ou transferidor estipula um valor máximo para a transferência, ou seja, a soma total das transferências não pode ultrapassar um valor estabelecido (Mendes, 2004). De acordo com Shah (2007), a limitação pode permitir ou assegurar ao concessor certo controle sobre os custos dos programas de transferência. Já as transferências condicionais com contrapartida e ilimitadas são empregadas para corrigir ineficiências na provisão de bens públicos quando externalidades ou spillovers são constatados.

O tipo de transferência a ser utilizado, no geral, depende da finalidade dessa transferência. Shah (2007, p. 15-16) elenca 15 diretrizes que devem ser consideradas para o desenho das transferências com a finalidade de assegurar a eficiência e equidade na provisão de serviços e saúde fiscal dos governos locais:

- Clareza dos objetivos: os objetivos da transferência devem ser especificados de forma clara e precisa para orientar o projeto da transferência;

- Autonomia: os governos subnacionais devem ter total independência e flexibilidade na definição de prioridades. Eles não devem ser limitados pela estrutura categórica dos programas nem pelas incertezas associadas à tomada de decisões. A distribuição das competências tributárias permitir que governos subnacionais introduzam suas próprias alíquotas de impostos, compartilhamento de receita baseado em fórmulas ou transferências em bloco - é consistente com esse objetivo;

- Adequação da receita: os governos subnacionais devem ter receitas adequadas ou suficientes para cumprir as responsabilidades designadas;

- Capacidade de resposta: o programa de transferência deve ser flexível o suficiente para acomodar mudanças imprevistas na situação fiscal dos beneficiários;

- Equidade (justiça): os recursos alocados devem variar diretamente com fatores referentes à necessidade fiscal e inversamente com a capacidade tributária de cada jurisdição;

- Previsibilidade: os mecanismos de financiamento devem garantir a previsibilidade das ações dos governos subnacionais, publicando projeções anuais de disponibilidade de financiamento por um período de cinco anos. A fórmula da transferência deve especificar tetos e pisos para as flutuações anuais. Quaisquer alterações importantes na fórmula devem ser acompanhadas de direitos adquiridos; 
- Transparência: tanto a fórmula como as alocações devem ser amplamente divulgadas a fim de alcançar consenso tão amplo quanto possível sobre os objetivos e o funcionamento do programa;

- Eficiência: o desenho da transferência deve ser neutro em relação às escolhas dos governos subnacionais de alocação de recursos para diferentes setores ou tipos de atividade;

- Simplicidade: a alocação das transferências deve basear-se em fatores objetivos sobre os quais as unidades individuais têm pouco controle. A fórmula deve ser de fácil entendimento, para não premiar a habilidade de garantir transferências;

- Incentivo: o desenho das transferências deve fornecer incentivos para uma boa gestão fiscal e desestimular práticas ineficientes. Transferências específicas para financiar déficits dos governos subnacionais não devem ser realizadas;

- Alcance: todos os programas financiados por transferências criam vencedores e perdedores. Deve-se dar atenção à identificação dos beneficiários e aos que serão afetados negativamente para determinar a utilidade geral e a sustentabilidade do programa;

- Salvaguarda dos objetivos do transferidor: os objetivos do transferidor são mais bem salvaguardados por meio de transferências que especifiquem os resultados a serem atingidos (transferências baseadas em outputs) e proporcionem ao beneficiário flexibilidade na utilização dos recursos;

- Viabilidade: o programa de transferência deve considerar as restrições orçamentárias dos transferidores. Isso sugere que as transferências devem ser com contrapartida e limitada;

- Focalização: cada programa de transferência deve concentrar-se em um único objetivo;

- Accountability por resultados: o transferidor deve ser responsável pelo desenho e pelo funcionamento do programa. $\mathrm{O}$ beneficiário deve ser responsável perante o transferidor e os cidadãos pela integridade financeira e resultados - isto é, melhorias no desempenho da prestação de serviços.

Shah (2007) indica, ainda, a possibilidade de ocorrência de conflitos entre as diretrizes. Ou seja, algumas dessas diretrizes podem ficar ausentes no desenho das transferências em decorrência da necessidade do aparecimento de outras.

\section{FEDERALISMO FISCAL E A EXPERIÊNCIA DO ESTADO DO CEARÁ NA EDUCAÇÃO}

A Constituição Federal de 1988 (Brasil, 1988) determina em seu artigo 211 que os três níveis de governo devem organizar seus sistemas de ensino por meio do regime de colaboração, definido pelo Ministério da Educação (MEC) como

a expressão e a forma de organização dos sistemas de ensino por meio de relações de colaboração, garantindo o cumprimento das responsabilidades definidas nas normas de cooperação e nas novas regras de financiamento, todas direcionadas pelos referenciais de qualidade expressos na [Lei de Diretrizes e Bases da Educação Nacional] LDB. (Brasil, 2015) 
É possível verificar que há a descentralização das políticas educacionais, pois, no artigo supracitado, se destaca como de responsabilidade da União a organização do sistema federal de ensino, assim como a dos territórios, o financiamento das instituições de ensino públicas federais e o exercício da função redistributiva e supletiva mediante a assistência técnica e financeira aos estados, ao Distrito Federal e aos municípios. Também por meio da Constituição, tem-se que os municípios devem atuar prioritariamente no ensino fundamental e na educação infantil, e o ensino médio e o ensino fundamental correspondem a prioridades dos estados e do Distrito Federal.

Nota-se, dessa forma, tal qual apontam Abrucio e Seggatto (2014, p. 52), que "o modelo proposto pela Constituição nas políticas sociais articula autonomia e interdependência entre os entes". Na educação, por exemplo, tem-se um regime de colaboração, pois duas redes distintas, estadual e municipal, são responsáveis pelo ensino fundamental. Essa competência compartilhada exige maior coordenação entre os entes, tanto para a formulação quanto para a implementação de políticas (Abrucio, Seggatto e Pereira, 2016).

Apesar de a Constituição Federal de 1988 (Brasil, 1988) determinar a cooperação entre os entes para a execução das políticas educacionais por meio do regime de colaboração, ela não estabeleceu como essa articulação deve ser realizada. Tal articulação é uma das dificuldades iniciais de implementação de arranjos de coordenação e cooperação entre os entes (Abrucio, Franzese e Sano, 2010), e, para Abrucio, Seggatto e Pereira (2016), a descentralização que ocorreu imediatamente após a Constituição Federal de 1988 se caracterizou como desorganizada, uma vez que a coordenação federal ficou ausente e, além disso, o fluxo financeiro intergovernamental não favoreceu a redução das desigualdades nem a universalização da educação.

Assim, com o intuito de reduzir tais desigualdades de gasto entre os entes e, com isso, assegurar melhor distribuição dos recursos, em janeiro de 1998 foi implantado, em âmbito nacional, o Fundo de Manutenção e Desenvolvimento do Ensino Fundamental e de Valorização do Magistério (Fundef), instituído pela Emenda Constitucional no 14 (Brasil, 1996a). Entre as alterações propostas pelo Fundef, destacam-se aquelas relacionadas à estrutura de financiamento do ensino fundamental, uma vez que parte dos recursos constitucionalmente vinculados à educação ficou subvinculada a esse nível de ensino.

Já por meio da Emenda Constitucional no 53 (Brasil, 2006), foi instituído o Fundo de Manutenção e Desenvolvimento da Educação Básica e de Valorização dos Profissionais da Educação (Fundeb), em substituição ao Fundef. O Fundeb configura-se como uma transferência com condicionalidades baseada em inputs em que 60\% dos recursos devem ser destinados aos profissionais do magistério da educação básica pública e $40 \%$ para as demais despesas, como as de manutenção da escola.

Já a mudança na legislação referente ao ICMS no Ceará que, juntamente com outras ações, tem provocado melhoria nos índices de educação corresponde a uma transferência com condicionalidades fundamentada em outputs. A lei anterior de tal estado (Brasil, 1996b) baseava-se em uma transferência com condicionalidades em inputs e determinava os seguintes critérios de distribuição da parcela discricionária: $12,5 \%$ de acordo com a proporção de gastos com desenvolvimento e manutenção da educação; 7,5\% distribuída equitativamente entre todos os municípios, ou seja, correspondente à parte igualitária; e 5\% conforme a população de cada município. 
Segundo esses critérios, a proporção da parcela discricionária que deveria ser repassada não demandava esforços municipais para aprimorar seus índices ou desempenho nem, em decorrência disso, para receber mais recursos. O único critério que poderia, de certa forma, modificar o montante a ser recebido equivalia aos gastos com educação. No entanto, de acordo com Brandão (2014, p. 40), "não se trata de tarefa simples visto que o recurso transferido do Fundeb era o que tinha peso maior nesta conta".

Com a revogação daquela lei e a promulgação da Lei no 14.023 (Brasil, 2007), a distribuição da parcela discricionária passou a apresentar características de transferência com condicionalidades baseadas em outputs. Desse modo, a distribuição dos recursos passou a ser realizada por índices alcançados pelos municípios: 18\% de acordo com o IQE, 5\% em função do Índice de Qualidade da Saúde (IQS) e 2\% segundo o Índice de Qualidade do Meio Ambiente (IQM).

Pesquisas anteriores apontam, entre os principais achados, o impacto positivo nos índices de educação no estado do Ceará. Brandão (2014) constatou que os municípios cearenses que tiveram sua receita advinda do ICMS reduzida após a alteração, municípios perdedores, apresentaram crescimento superior de seus indicadores de educação em relação àqueles que obtiveram aumento dos recursos após a mudança, os municípios ganhadores.

Observou-se que a mudança dos critérios de distribuição da parcela discricionária, de condicionalidade baseada em inputs para outputs, foi um fator que contribuiu para que o estado do Ceará apresentasse melhorias em seus índices educacionais.

\section{COLETA DE DADOS E FORMAÇÃO DE GRUPOS}

As fontes dos dados utilizados foram as leis estaduais referentes aos critérios de distribuição da parcela discricionária. Foi construída uma base com os dados de identificação tanto das leis revogadas quanto das vigentes, ambas com as suas respectivas alterações, se existentes. A classificação em revogada ou vigente foi realizada considerando o período da coleta das leis, entre fevereiro e março de 2018. Tabularam-se 65 leis, 15 classificadas em revogadas e 50 em vigentes.

A busca das leis ocorreu para os 26 estados e o Distrito Federal, no entanto há particularidades que devem ser apontadas quanto ao Distrito Federal, ao Acre e à Paraíba. No que se refere ao Distrito Federal, não é uma atribuição do referido ente promover a distribuição da cota-parte do ICMS, mas sim receber do estado de Goiás a parte que lhe cabe (Barros, 2001). Já o Acre, de acordo com Barros (2001), não legislou acerca dos critérios que utilizaria para o rateio da parcela discricionária. Nesse estado, $5 \%$ da parcela discricionária pertencente aos municípios é distribuída de acordo com critérios ambientais (Brasil, 2004b) e o restante conforme os critérios de distribuição do FPM. Na Paraíba, a lei que dispõe sobre os critérios de participação dos municípios na arrecadação do ICMS está suspensa, pelo fato de estabelecer critérios de distribuição que, somados, totalizam $30 \%$, isto é, ultrapassam os $25 \%$, estando, assim, em desacordo com a Constituição Federal de 1988 (Secretaria de Estado da Fazenda da Paraíba, 2011). Portanto, o Distrito Federal não foi incluído nos agrupamentos nem nas análises feitas, porém os estados do Acre e da Paraíba foram abordados. De qualquer modo, é importante considerar os apontamentos supramencionados. 
Das 65 leis localizadas, foram coletados os critérios de distribuição da parcela discricionária da cota-parte do ICMS, bem como o percentual destinado para cada critério. A coleta totalizou 173 critérios, sendo 45 extraídos de leis revogadas e 128 de leis vigentes. Em decorrência da quantidade de critérios, categorias foram formadas para agrupar os critérios e viabilizar as análises.

Para a criação de uma categoria, utilizou-se a condição de que deveriam existir três critérios ou mais cuja temática fosse igual ou muito semelhante. Os critérios empregados por apenas um ou dois estados foram agrupados na categoria outros. Uma única exceção foi aplicada a essa regra de categorização, para a categoria coeficiente social, uma vez que esse critério é usado somente pelo Mato Grosso (Brasil, 2004a), com percentual de $11 \%$. Como o critério corresponde a $44 \%$ da parcela discricionária (11\% do total de $25 \%$ ), uma categoria foi criada para esse critério.

Assim, 14 categorias foram instituídas e são exibidas no Quadro 2. Adicionalmente, apresentam-se a descrição e a indicação, se o cálculo dos critérios de distribuição agrupados na categoria é padronizado, ou seja, se é realizado da mesma maneira entre os estados que utilizam o critério, ou se tal cálculo é apurado de modo específico em cada ente. Constataram-se casos em que há variações na fonte dos dados empregados para o cálculo dos critérios, porém a lógica não se altera. Nesses casos, a categoria foi classificada com cálculo padronizado.

Com o intuito de caracterizar as categorias, foram levantadas estatísticas descritivas tanto para as leis revogadas quanto para as vigentes, as quais estão expostas na Tabela 1 e compreendem: indicação da quantidade de critérios classificados na categoria (colunas 2 e 8); quantidade de estados que utilizam critérios de distribuição classificados na categoria (colunas 3 e 9); o menor e o maior valor percentual dos critérios da categoria, bem como a indicação a qual ou quais estados pertencem (colunas 4,5,10 e 11); a média entre os percentuais dos critérios de distribuição classificados na mesma categoria (colunas 6 e 12); e o desvio padrão de tais percentuais (colunas 7 e 13).

Observa-se que há maior número de critérios de distribuição nas leis vigentes, 128 , do que nas leis revogadas, 45 , entretanto apenas 13 estados tiveram leis revogadas. Além disso, determinadas categorias apresentam modificações significativas no que se refere à quantidade de critérios entre as leis revogadas e as vigentes. Entre elas, pode-se destacar a categoria meio ambiente, a qual reúne o maior número de critérios de distribuição contidos nas leis vigentes. Todavia, a categoria com a maior média corresponde à parte igualitária, que apresenta o percentual médio de $12,48 \%$ entre as leis vigentes e $10,68 \%$ entre as leis revogadas. A categoria equalização, no caso das leis revogadas, apresenta média de 25\%, porém somente o estado de Pernambuco recorria a tal critério de distribuição.

No que se refere aos critérios de distribuição classificados na categoria saneamento (Tabela 1 e parte 2 da Tabela 2), é importante indicar que as leis vigentes dos estados de Piauí, Mato Grosso do Sul, Minas Gerais e Espírito Santo também incluem critérios que poderiam ser classificados nessa categoria. Todavia, as leis desses entes apontam somente o percentual global para o critério, o que inviabilizou a devida segregação. Logo, o critério apresentado por Piauí, Mato Grosso do Sul e Minas Gerais foi incluído na categoria meio ambiente e pelo Espírito Santo na categoria saúde. A lei revogada de Minas Gerais também exibia critério que seria classificado na categoria saneamento, porém a impossibilidade de segregação resultou no encaixe do percentual na categoria meio ambiente. 
Quadro 2-Categorias.

\begin{tabular}{|c|c|}
\hline \multicolumn{2}{|r|}{ Parte 1: categorias com cálculo padronizado } \\
\hline $\begin{array}{l}\text { Parte } \\
\text { igualitária }\end{array}$ & $\begin{array}{l}\text { Corresponde à parte dos recursos que são distribuídos equitativamente entre os } \\
\text { municípios. Também é denominada cota mínima. }\end{array}$ \\
\hline $\begin{array}{l}\text { Área } \\
\text { geográfica }\end{array}$ & $\begin{array}{l}\text { Diretamente proporcional à superfície territorial do município. É o índice resultante } \\
\text { da relação percentual entre a área do município e a área total do respectivo estado. }\end{array}$ \\
\hline População & $\begin{array}{l}\text { Corresponde ao índice diretamente proporcional resultante da relação entre a } \\
\text { população total de cada município e a população total do respectivo estado. }\end{array}$ \\
\hline $\begin{array}{l}\text { Valor } \\
\text { adicionado } \\
\text { fiscal (VAF) }\end{array}$ & $\begin{array}{l}\text { Parcela adicional ao montante a ser recebido pelo ente municipal em decorrência do } \\
\text { valor adicionado, isto é, dos } 75 \% \text { da cota-parte pertencente aos municípios a serem } \\
\text { distribuídos de acordo com o princípio da derivação (Brasil, 1988). }\end{array}$ \\
\hline \multicolumn{2}{|r|}{ Parte 2: categorias com cálculo específico } \\
\hline Meio ambiente & $\begin{array}{l}\text { Compreende critérios relativos à proporção de unidades de conservação } \\
\text { ambiental públicas e/ou privadas, tais como áreas de preservação ambiental, } \\
\text { comunidades/terras indígenas, estações ecológicas, parques, reservas florestais, } \\
\text { florestas e hortos florestais. }\end{array}$ \\
\hline Agropecuária & $\begin{array}{l}\text { Compreende critérios relativos ao repasse de recursos baseados na área cultivada, ou } \\
\text { seja, a produção agropecuária no território do município em relação à produção do } \\
\text { respectivo estado. Determinadas legislações estaduais apontam, para este critério, } \\
\text { a produtividade primária, incluindo a produção agrícola, pecuária, extrativa e de } \\
\text { alimentos, assim como a comercialização de produtos agrícolas e hortigranjeiros. }\end{array}$ \\
\hline Receita própria & $\begin{array}{l}\text { Critério calculado, na maioria dos casos, com base em dados fornecidos pelos } \\
\text { Tribunais de Contas dos estados. Corresponde ao índice resultante do percentual } \\
\text { da receita própria de cada município ou do percentual entre o valor da receita } \\
\text { tributária própria de cada município e a soma da receita tributária própria de todos } \\
\text { os municípios do ente estadual. Determinados entes incluem no cálculo o valor } \\
\text { das transferências de recursos federais e estaduais recebidas pelo município ou a } \\
\text { participação relativa na arrecadação per capita de tributos municipais de todos os } \\
\text { municípios do estado. }\end{array}$ \\
\hline Saúde & $\begin{array}{l}\text { Compreende critérios relativos à saúde e pode ser calculado com base no repasse } \\
\text { de recursos em função do índice da qualidade da saúde municipal, obtido por meio } \\
\text { de indicadores de mortalidade infantil; na relação entre os gastos com saúde per } \\
\text { capita do ente municipal e o somatório dos gastos com saúde per capita de todos } \\
\text { os municípios do respectivo estado; de maneira igualitária entre os municípios que } \\
\text { estejam enquadrados na condição de gestão mais avançada do Sistema Municipal } \\
\text { de Saúde, de acordo com a norma operacional básica do Sistema Único de Saúde } \\
\text { (SUS), entre outros. }\end{array}$ \\
\hline Educação & $\begin{array}{l}\text { Compreende critérios relativos ao repasse de recursos baseados em indicadores } \\
\text { educacionais, tais como: índice da qualidade da educação municipal, quantidade de } \\
\text { alunos matriculados, relação entre o total de alunos atendidos e a capacidade mínima } \\
\text { de atendimento pelo município. }\end{array}$ \\
\hline Equalização & $\begin{array}{l}\text { Calculado e distribuído de acordo com os seguintes critérios: proporcionalmente } \\
\text { à soma inversa dos índices de população, área geográfica e VAF de cada ente } \\
\text { municipal em relação ao total do ente estadual; igualmente entre todos os } \\
\text { municípios que não alcançarem o índice preestabelecido, entre outros. }\end{array}$ \\
\hline
\end{tabular}


Quadro 2-Continuação.

\begin{tabular}{|l|l|}
\hline $\begin{array}{l}\text { População } \\
\text { rural }\end{array}$ & $\begin{array}{l}\text { Compreende critérios que contemplam a proporção entre o número de propriedades } \\
\text { rurais cadastradas no município e as cadastradas no respectivo estado, assim como a } \\
\text { proporção resultante entre o número de habitantes da zona rural do município e a } \\
\text { população rural do ente estadual. }\end{array}$ \\
\hline Saneamento & $\begin{array}{l}\text { Compreende critérios relativos à promoção do tratamento de lixo domiciliar, } \\
\text { incluindo as unidades de compostagens ou de aterro sanitário, entre outros. }\end{array}$ \\
\hline $\begin{array}{l}\text { Coeficiente } \\
\text { social }\end{array}$ & $\begin{array}{l}\text { Correspondente à divisão do percentual pela soma do inverso do índice de } \\
\text { desenvolvimento humano (IDH) de todos os municípios existentes no estado } \\
\text { multiplicado pelo inverso do IDH de cada município (Brasil, 2004a). }\end{array}$ \\
\hline Outros & $\begin{array}{l}\text { Compreende critérios de distribuição em função de programas de integração } \\
\text { tributária, segurança pública, patrimônio cultural, turismo, esporte, participantes de } \\
\text { consórcio para prestação de serviços de saúde e municípios mineradores, municípios } \\
\text { sede de estabelecimentos penitenciários, mais populosos, entre outros. }\end{array}$ \\
\hline
\end{tabular}

A Tabela 2 traz os critérios de distribuição da parcela discricionária de cada estado, classificados nas categorias. A parte 1 dessa tabela refere-se aos critérios de distribuição cujas leis já foram revogadas, e a parte 2, às leis vigentes. Os destaques (em cinza) dizem respeito aos estados que utilizam os mesmos critérios de distribuição, com variações apenas nos percentuais destinados.

Tanto nas leis revogadas quanto nas leis vigentes, somente dois grupos foram formados em cada parte da tabela, uma vez que, para as leis revogadas, somente os estados do Amazonas, do Amapá, da Paraíba e de Alagoas (parte 1 da Tabela 2) e,para as leis vigentes, Roraima, Sergipe, Amazonas, Maranhão e Rio Grande do Norte (parte 2 da Tabela 2) possuem critérios de distribuição enquadrados nas mesmas categorias.

Além disso, é importante observar que há discrepâncias significativas entre a quantidade de critérios empregados em cada ente estadual, haja vista que o estado de Minas Gerais, por exemplo, realiza a distribuição empregando critérios classificados em dez categorias, enquanto Roraima e Sergipe (leis vigentes) fazem a distribuição apenas por meio de critérios referentes à parte igualitária.

No que concerne aos critérios de distribuição classificados na categoria educação, as leis revogadas tanto de Minas Gerais quanto do Ceará apresentavam critérios de distribuição da parcela discricionária baseados na educação (parte 1 da Tabela 2). Já em relação às leis vigentes, além desses dois entes estaduais, Amapá e Pernambuco determinam a distribuição aos municípios utilizando critérios com base na educação (parte 2 da Tabela 2).

No entanto, dos estados que utilizam critérios de distribuição dispostos na categoria educação, somente a legislação vigente do estado do Ceará se fundamenta em condicionalidade de transferência baseada em output, o IQE. Os demais critérios de ambos os conjuntos legislativos se referem à condicionalidade baseada em input.

Adicionalmente, um segundo agrupamento foi elaborado com o intuito de identificar o ano das leis bases que tratam da parcela discricionária, assim como a quantidade de leis posteriores que alteraram os critérios de distribuição aos municípios, o ano da última alteração realizada e, por fim, o percentual de critérios de distribuição que não foram alterados desde as leis bases (Tabela 3). 


\begin{tabular}{|c|c|c|c|c|c|c|c|c|c|c|c|c|c|c|c|c|}
\hline & 高 & 索 & $\underset{q}{q}$ & $\begin{array}{l}\infty \\
\infty \\
i\end{array}$ & $\mid \begin{array}{l}\hat{6} \\
\hat{n}\end{array}$ & $\left|\begin{array}{c}n \\
n \\
n\end{array}\right|$ & $\mid \begin{array}{l}3 \\
- \\
-1\end{array}$ & ตु. & $\stackrel{R}{\stackrel{R}{-}}$ & ă & $\stackrel{n}{n}$ & in & กิ & 1 & $\stackrel{+}{+}$ & \\
\hline \multirow{7}{*}{ 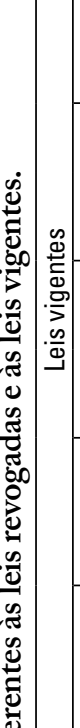 } & $\stackrel{\frac{\pi}{0}}{\stackrel{\oplus}{\Sigma} \cong}$ & $\begin{array}{l}\stackrel{\infty}{+} \\
\underset{\exists}{\mathfrak{y}}\end{array}$ & $\stackrel{\stackrel{\sim}{m}}{\stackrel{*}{*}}$ & $\stackrel{\vec{n}}{n}$ & $\left|\begin{array}{l}2 \\
0 \\
\text { in }\end{array}\right|$ & $\left|\begin{array}{l}2 \\
\text { ले }\end{array}\right|$ & $\mid \begin{array}{l}n \\
\hat{n} \\
\sim\end{array}$ & f̊ & $\stackrel{\text { f }}{m}$ & $\begin{array}{l}n \\
\text { n. }\end{array}$ & $\hat{\sigma}$ & 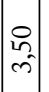 & $\wedge$ & 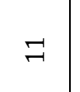 & $\stackrel{0}{\stackrel{7}{m}}$ & \\
\hline & \multirow{2}{*}{ 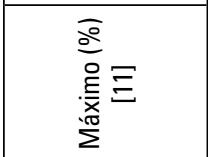 } & 華 & $\stackrel{\circ}{\models}$ & $\bar{a}$ & क & $\mid \frac{1}{2}$ & कि & 됭 & 扛 & 된 & $\underline{\not{L}}$ & $\stackrel{\oplus}{\sim}$ & Ōర & \multirow{2}{*}{ 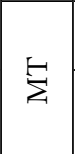 } & $\ddot{\dot{\varepsilon}}$ & \\
\hline & & $\stackrel{\stackrel{2}{N}}{ }$ & $2 n$ & $\stackrel{ }{-1}$ & $\rightarrow$ & $\infty$ & in & $\approx$ & $n_{n}^{n}$ & $\stackrel{\infty}{\sim}$ & $\infty$ & in & $\stackrel{ }{-1}$ & & in & \\
\hline & \multirow{2}{*}{ 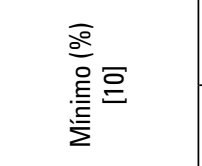 } & $\ddot{\tilde{\sim}}$ & 公 क & $\sum$ & $\stackrel{0}{\approx}$ & $\stackrel{0}{\Sigma}$ & . & $\bar{x}$ & $\sum_{i}^{0}$ & $\dot{\theta}_{i}$ & થి & 되시 & 落 & $\begin{array}{l}\text { oे } \\
\vec{\xi}\end{array}$ & $\approx$ & \\
\hline & & $\sim$ & $-r$ & $3_{0}^{2}$ & ?n. & -1 & $\dot{\sigma}^{\circ}$ & $\hat{-}$ & $\sim$ & $\sim$ & in & $\sim$ & $\dashv$ & & $\tilde{n}_{0}$ & \\
\hline & 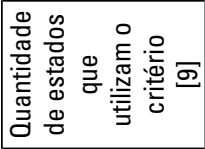 & $\stackrel{\infty}{\sim}$ & $\stackrel{\beth}{\neg}$ & $\stackrel{0}{-1}$ & $\stackrel{2}{\sim}$ & $\wedge$ & $\wedge$ & in & in & $\nabla$ & $m$ & m & $m$ & - & 0 & \\
\hline & 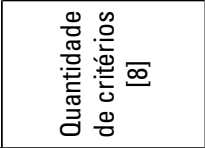 & $\stackrel{\infty}{\rightarrow}$ & $\stackrel{\llcorner}{\sim}$ & $\stackrel{0}{-1}$ & $\stackrel{2}{-1}$ & $\wedge$ & $\wedge$ & 0 & 0 & $\nabla$ & $\nabla$ & $\infty$ & $m$ & $r$ & $\stackrel{9}{\rightarrow}$ & $\stackrel{\infty}{\sim}$ \\
\hline \multirow{6}{*}{ 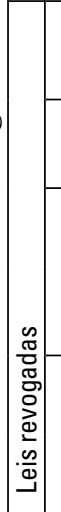 } & 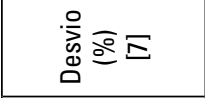 & 호 & I & ले & 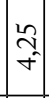 & $\hat{N}$ & 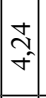 & ' & I & $\stackrel{\text { I }}{\text { N }}$ & 1 & I & $\begin{array}{l}\hat{\infty} \\
+ \\
+\end{array}$ & 1 & I & \\
\hline & $\sum_{\Sigma}^{\frac{\pi}{\varrho}} \cong \bar{\Xi}$ & $\begin{array}{l}\infty \\
0 \\
0 \\
0\end{array}$ & $r$ & $\begin{array}{l}\hat{n} \\
\stackrel{+}{*}\end{array}$ & $\begin{array}{l}10 \\
12 \\
n\end{array}$ & กิ & in & $\stackrel{\sim}{\sim}$ & $\sim$ & $\stackrel{n}{n}$ & in & I & $\begin{array}{l}\hat{0} \\
\infty\end{array}$ & 1 & $\vec{m}$ & \\
\hline & $\bar{\circ}$ & $\stackrel{\not 1}{\not}$ & \multirow{2}{*}{$\stackrel{0}{\Sigma}$} & $\bar{a}$ & 安 & $\approx$ & 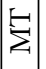 & \multirow{2}{*}{ 돈 } & \multirow{2}{*}{$\stackrel{0}{\Sigma}$} & 된 & \multirow{2}{*}{$\mathscr{2}$} & & O & & $\sum_{\Sigma}^{0}$ & \\
\hline & 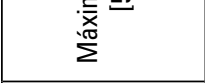 & $\stackrel{\stackrel{\sim}{\sim}}{\sim}$ & & $\hat{\imath}$ & 2 & $\left|\begin{array}{l|}n^{2} \\
n^{2}\end{array}\right|$ & $\infty$ & & & 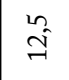 & & & $\stackrel{\text { 늠 }}{\sim}$ & & $\vec{m}$ & \\
\hline & \multirow{2}{*}{$\begin{array}{l}\bar{a} \\
\text { 高导 } \\
\text { 高 }\end{array}$} & $\stackrel{5}{\Sigma}$ & $\dashv$ & $\sum_{\Sigma}^{0}$ & $\bigcirc$ & 足 & $\mid \begin{array}{c}0 \\
\Sigma\end{array}$ & $\stackrel{\imath}{\sim}$ & $\sim$ & $\sum_{\Sigma}^{U}$ & in & & $\stackrel{0}{\Sigma}$ & & $\stackrel{0}{\Sigma}$ & \\
\hline & & N & 1 & - & 는 & -1 & $\sim$ & 1 & 1 & $\sim$ & 1 & & $\stackrel{\nabla}{F}$ & & $\vec{m}$ & \\
\hline & 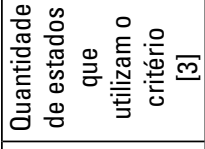 & $\exists$ & $\neg$ & $\wedge$ & 의 & $\sim$ & $\sim$ & -1 & $\neg$ & $\sim$ & $\rightarrow$ & 1 & $\nabla$ & 1 & - & \\
\hline & 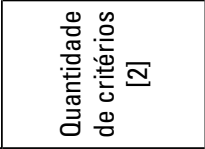 & $\exists$ & - & $\wedge$ & 욱 & $\sim$ & $\sim$ & -1 & - & $\sim$ & 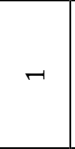 & 1 & $\nabla$ & 1 & $n$ & $\stackrel{\text { ำ }}{7}$ \\
\hline & 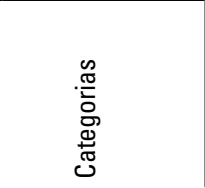 & | & 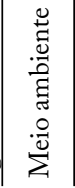 & 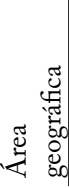 & 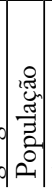 & 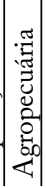 & 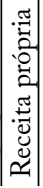 & 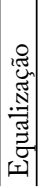 & $\begin{array}{l}\tilde{z} \\
\text { ñ } \\
\text { ñ }\end{array}$ & 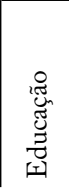 & 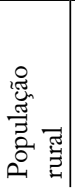 & 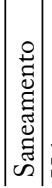 & 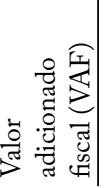 & 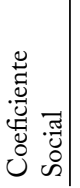 & 总 & 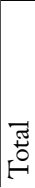 \\
\hline
\end{tabular}




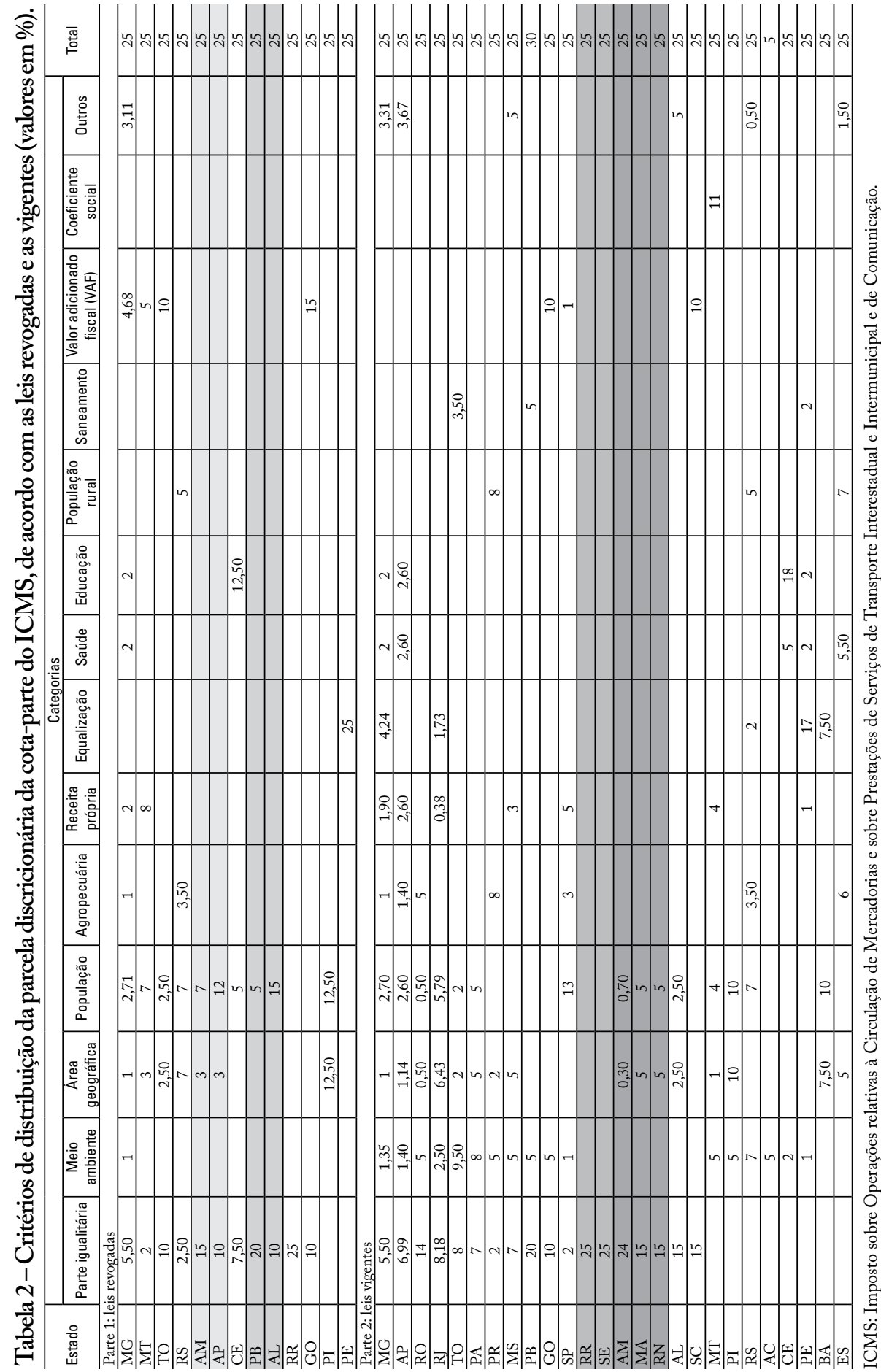


Nota-se que desde 2012 não houve alterações nas leis estaduais referentes à distribuição da parcela discricionária. Ademais, há leis que se encontram vigentes e sem alterações desde 1990, como é o caso em Sergipe, e 1992, no Maranhão.

Tabela 3 - Anos das leis bases, revogadas e vigentes, da parcela discricionária da cota-parte do ICMS, informações sobre suas alterações e percentual de critérios de distribuição não alterados.

\begin{tabular}{|c|c|c|c|c|c|c|c|c|}
\hline \multirow[b]{2}{*}{ Estado } & \multicolumn{4}{|c|}{ Leis revogadas } & \multicolumn{4}{|c|}{ Leis vigentes } \\
\hline & $\begin{array}{l}\text { Ano } \\
\text { da } \\
\text { lei } \\
\text { base }\end{array}$ & $\begin{array}{l}\text { Quantidade } \\
\text { de } \\
\text { alterações } \\
\text { (nº de leis) }\end{array}$ & $\begin{array}{c}\text { Ano da } \\
\text { lei da } \\
\text { última } \\
\text { alteração }\end{array}$ & $\begin{array}{c}\text { \% de } \\
\text { critérios } \\
\text { não } \\
\text { alterados }\end{array}$ & $\begin{array}{l}\text { Ano } \\
\text { da } \\
\text { lei } \\
\text { base }\end{array}$ & $\begin{array}{l}\text { Quantidade } \\
\text { de } \\
\text { alterações } \\
\text { (n }{ }^{0} \text { de leis) }\end{array}$ & $\begin{array}{c}\text { Ano da } \\
\text { lei da } \\
\text { última } \\
\text { alteração }\end{array}$ & $\begin{array}{c}\% \text { de } \\
\text { critérios } \\
\text { não } \\
\text { alterados }\end{array}$ \\
\hline ES & & & & & 1989 & 2 & 1997 & 0 \\
\hline $\mathrm{SC}$ & & & & & 1989 & 1 & 1990 & 0 \\
\hline $\mathrm{RN}$ & & & & & 1997 & 1 & 2009 & 0 \\
\hline PI & 1989 & 0 & & 100 & 1998 & 2 & 2009 & 0 \\
\hline $\mathrm{PE}$ & 1990 & 0 & & 100 & 2000 & 1 & 2003 & 0 \\
\hline $\mathrm{AL}$ & 1991 & 0 & & 100 & 1997 & 1 & 2008 & 25 \\
\hline RS & 1981 & 0 & & 100 & 1997 & 3 & 2009 & 33 \\
\hline MT & 1985 & 0 & & 100 & 2000 & 1 & 2004 & 40 \\
\hline SP & & & & & 1981 & 1 & 1993 & 43 \\
\hline PA & & & & & 1991 & 1 & 2012 & 50 \\
\hline PR & & & & & 1990 & 2 & 1998 & 57 \\
\hline MS & & & & & 1991 & 2 & 2011 & 60 \\
\hline $\mathrm{RO}$ & & & & & 1994 & 1 & 1996 & 60 \\
\hline RJ & & & & & 1996 & 1 & 2007 & 83 \\
\hline SE & & & & & 1990 & 0 & & 100 \\
\hline MA & & & & & 1992 & 0 & & 100 \\
\hline RR & 1991 & 0 & & 100 & 1993 & 0 & & 100 \\
\hline $\mathrm{AP}$ & 1993 & 0 & & 100 & 1996 & 0 & & 100 \\
\hline $\mathrm{BA}$ & & & & & 1997 & 0 & & 100 \\
\hline $\mathrm{AM}$ & 1990 & 0 & & 100 & 2002 & 0 & & 100 \\
\hline $\mathrm{TO}$ & 1995 & 0 & & 100 & 2002 & 0 & & 100 \\
\hline $\mathrm{AC}$ & & & & & 2004 & 0 & & 100 \\
\hline $\mathrm{CE}$ & 1996 & 0 & & 100 & 2007 & 0 & & 100 \\
\hline MG & 1995 & 1 & 2000 & 92 & 2009 & 0 & & 100 \\
\hline $\mathrm{PB}$ & 1981 & 1 & 1998 & 50 & 2011 & 0 & & 100 \\
\hline $\mathrm{GO}$ & 2000 & 0 & & 100 & 2012 & 0 & & 100 \\
\hline
\end{tabular}

ICMS: Imposto sobre Operações relativas à Circulação de Mercadorias e sobre Prestações de Serviços de Transporte Interestadual e Intermunicipal e de Comunicação. 
Destaca-se, também, que o estado do Rio Grande do Sul corresponde ao ente estadual com a maior quantidade de alterações na lei base da distribuição da parcela discricionária - foram realizadas três alterações, sendo a última em 2009 -, e somente $33 \%$ dos critérios de distribuição não foram alterados.

Ainda, fez-se um terceiro agrupamento com base nas leis revogadas e vigentes da distribuição da parcela discricionária. Nele, as distribuições realizadas pelos estados foram classificadas em tradicionais, quase tradicionais e não tradicionais. Para isso, os conceitos de leis tradicionais e não tradicionais foram extraídos de Brandão (2014). Segundo o autor, leis tradicionais de distribuição de ICMS incluem: “(a) um componente ligado ao Valor Adicionado Fiscal; (b) um componente equitativo - ou seja, distribuído de forma igualitária a todos os municípios; e, em alguns estados, (c) um componente relacionado a dados demográficos ou territoriais" (Brandão, 2014, p. 29). Por outro lado, Brandão (2014) considera leis não tradicionais de distribuição de ICMS aquelas que contêm "indicadores sociais, econômicos, financeiros e/ ou ambientais na divisão dos $25 \%$ dos recursos sobre os quais cabe a eles definir a regra de distribuição" (Brandão, 2014, p. 29).

O agrupamento exibido no Quadro 3 utiliza os conceitos de classificação de Brandão (2014), mas não se baseia exclusivamente neles, uma vez que as leis foram classificadas em tradicionais, quase tradicionais e não tradicionais. As seguintes categorias foram consideradas como tradicionais: parte igualitária, área geográfica, população e VAF. Por conseguinte, as dez categorias restantes foram classificadas como não tradicionais: meio ambiente, agropecuária, receita própria, equalização, saúde, educação, população rural, saneamento, coeficiente social e outros.

Assim sendo, a lei estadual foi classificada como tradicional se os $25 \%$ da parcela discricionária foi ou é distribuída de acordo com critérios classificados nas categorias consideradas tradicionais. Como quase tradicionais foram classificadas as leis estaduais que destinam entre 15 e $24,99 \%$ da parcela discricionária por meio de critérios classificados nas categorias tradicionais. Por fim, entendem-se como leis não tradicionais aquelas que distribuem menos de $15 \%$ da parcela discricionária por meio de critérios pertencentes às categorias tradicionais. Os percentuais empregados para a classificação estão na Tabela 2 .

Quadro 3 - Classificação das leis estaduais em tradicional, quase tradicional e não tradicional.

\begin{tabular}{|l|c|c|}
\hline Estados & Leis revogadas & Leis vigentes \\
\hline AM, RR & Tradicional & \multirow{2}{*}{ Tradicional } \\
\hline MA, RN, SC, SE & - & \multirow{2}{*}{ Quase tradicional } \\
\hline AL, GO, PB, PI & Tradicional & \multirow{2}{*}{ Não tradicional } \\
\hline BA, PA, RJ, RO, SP & - & \\
\hline AP, TO & Tradicional & \\
\hline MT, RS & Quase tradicional & \\
\hline CE, MG, PE & Não tradicional & \\
\hline AC, ES, MS, PR & - & \\
\hline
\end{tabular}


Constatou-se que as leis revogadas utilizavam quantidade superior de critérios de distribuição classificados em categorias tradicionais, 32 de 45 , e as leis vigentes empregam quantidade superior de critérios classificados em categorias não tradicionais, 76 de 128 (dados não tabulados).

Entre os estados que possuem leis já revogadas quanto à distribuição da parcela discricionária, verifica-se que apenas Ceará, Minas Gerais e Pernambuco possuíam leis não tradicionais. Ainda, até o momento da coleta das leis, a maioria dos estados, 11 , possui leis não tradicionais de distribuição da parcela discricionária, e a minoria, seis, realiza a distribuição por intermédio de critérios classificados em categorias tradicionais. Além disso, é importante destacar que há estados que alteraram suas leis tradicionais para leis não tradicionais, caso de Amapá e Tocantins, e os estados do Mato Grosso e do Rio Grande do Sul alteraram as leis de quase tradicionais para não tradicionais. De acordo com Brandão (2014), a utilização de leis não tradicionais pode ser considerada como um mecanismo para os estados estarem "incentivando municípios a melhorarem seu desempenho para, consequentemente, receberem mais recursos da cota-parte do ICMS”(Brandão, 2014, p. 29).

\section{DIRETRIZES PARA A ALTERAÇÃO DA LEGISLAÇÃO SOBRE A PARCELA DISCRICIONÁRIA}

Com base na abordagem de Shah (2007), na revisão de literatura sobre a experiência do Ceará e na análise das leis dos estados, foram levantadas 15 diretrizes que podem ser consideradas para a alteração da legislação com vistas a modificar os critérios de transferências da parcela discricionária pelos estados brasileiros de modo a favorecer um regime de colaboração no ensino fundamental por meio da inserção de condicionalidades baseadas em outputs. É importante indicar que a ordem das 15 diretrizes não se relaciona com a priorização que se deve dar a elas. A sequência foi escolhida com o propósito único de facilitar a leitura e o entendimento dos leitores.

A primeira diretriz refere-se à clareza dos objetivos. Os critérios de transferência devem se relacionar claramente com os resultados esperados da atuação dos gestores municipais no ensino fundamental. No caso do Ceará, a parcela destinada à educação é um dos componentes do desenho do regime de colaboração entre o estado e os municípios, com a finalidade de melhorar a qualidade da educação,já que a preocupação inicial era o número de crianças não alfabetizadas. Além do incentivo por meio do sistema de transferência, o estado realizou apoio técnico direcionado para a articulação do tripé: seleção e formação dos profissionais do magistério, material e acompanhamento pedagógico, e monitoramento e avaliação. As finalidades das transferências, em geral, não serão claras nem precisamente estabelecidas na legislação que determina os critérios de distribuição da parcela discricionária. Isso porque a legislação é um dos instrumentos de operacionalização das políticas definidas para atender às metas do plano de educação estadual e, portanto, deve ser compreendida em um contexto mais amplo da política educacional e fiscal.

A segunda diretriz é a autonomia. A modificação de transferências sem condicionalidades para transferências com condicionalidades pode reduzir a independência e a flexibilidade dos governos municipais na definição de suas prioridades. 
As transferências sem condicionalidades são oriundas daquelas realizadas pelos critérios tradicionais ou não tradicionais que se relacionam com características socioeconômicas dos municípios, e não com exigências quanto a inputs ou outputs.

A adequação da receita é a terceira diretriz a ser considerada. A exigência quanto ao alcance de determinados resultados no ensino fundamental pode gerar pressão nos orçamentos municipais, principalmente se o aumento da receita não for suficiente para promover os resultados esperados. Assim, mesmo que a transferência seja sem condicionalidade, na essência pode ser o contrário, uma vez que para o alcance dos resultados estabelecidos é necessária a destinação de parte da receita municipal mesmo sem restrições preestabelecidas quanto à destinação do recurso, pois os resultados devem ser alcançados para garantir o recebimento da transferência.

A quarta diretriz é a capacidade de resposta. Os municípios podem não conseguir alcançar/manter o padrão de resultados em determinados períodos em decorrência de mudanças inesperadas em sua situação fiscal, com consequências tais como: redução das transferências condicionais recebidas e, por conseguinte, piora em sua situação fiscal - haja vista que, mesmo que a transferência seja realizada por meio de um percentual preestabelecido, a redução da receita arrecadada pelo ente estadual acarreta a diminuição do valor a ser transferido ao ente municipal por causa da redução na base de cálculo, ou seja, a receita corrente líquida -, e/ou pressão na priorização quanto à alocação das despesas orçamentárias em funções/subfunções e/ou ações específicas.

Essa situação torna-se mais sensível quando os fatores que provocaram a modificação na situação fiscal não tenham afetado todas as municipalidades com a mesma intensidade. Nesse sentido, um aspecto importante da experiência do Ceará pode ser observado: a definição do critério geral por meio de lei e a operacionalização de tais critérios com a utilização de decreto. Assim, é possível acompanhar os resultados das transferências condicionais e realizar ajustes na operacionalização do seu critério, tanto para acomodar mudanças fiscais imprevistas quanto para avançar no alcance dos resultados no ensino fundamental quando o mesmo patamar tiver sido alcançado por todos os municípios. Nesse último caso, há a tendência de todos os municípios alcançarem determinado patamar na condição educacional — por exemplo, eliminação do analfabetismo — e a renovação da competição via alteração da meta - por exemplo, melhores resultados nos anos finais do ensino fundamental. Tal modificação não ensejaria a alteração da legislação, mas da operacionalização do critério via decreto, como ocorre no estado do Ceará por meio do Decreto no 29.306 (Brasil, 2008) e do Decreto no 30.796 (Brasil, 2011), por exemplo.

Além disso, no Ceará, a busca por resultados educacionais por meio do IQE reduz a influência da legislação, uma vez que incentiva a competição entre os municípios por aumento da obtenção de maiores índices para, consequentemente, garantir a adequação da receita, até mesmo como um mecanismo para aumentar o valor recebido. Há ainda que se mencionar que os resultados educacionais entre os estados são diferentes e, para aqueles com maiores níveis educacionais, a modificação nos indicadores é muito menos sensível, o que pode dificultar a operacionalização do regime de colaboração.

A eficiência é a quinta diretriz. A não adequação das receitas e a não consideração das mudanças na condição fiscal dos municípios podem levar a um efeito indesejado das transferências como é a influência nas escolhas dos gestores municipais quanto à alocação dos recursos para a educação em detrimento de outras áreas e/ou tipos de atividade. 
Outra diretriz a ser considerada é a equidade (justiça). A distribuição da parcela discricionária deve considerar as diferenças tanto na capacidade tributária quanto nas demandas por gasto em diferentes funções/subfunções de governo. Assim, no desenho da transferência, é necessário analisar se os critérios promovem ou não equidade. Por exemplo, a distribuição com base no VAF privilegia os maiores municípios, que, por sua vez, possuem maior capacidade de arrecadação, diferentemente do que ocorre com a parte igualitária, pois os municípios pequenos recebem um valor per capita maior. Pela experiência do estado do Ceará, os municípios que tiveram suas receitas de transferência aumentadas foram os de pequeno porte. Sendo assim, além de propiciar os melhores resultados em educação, também foram ao encontro de uma das características desejadas: a equidade (Albuquerque, 2009; Sales, 2011; Nogueira, 2012; Franca, 2014). Logo, os estados que não têm critérios que favorecem a equidade podem ter incentivos maiores para alterar a legislação sobre a parcela discricionária.

No contexto das diretrizes para a alteração da legislação sobre a parcela discricionária, o incentivo indica que a distribuição desta não deve premiar os municípios que apresentam práticas fiscais inadequadas, por exemplo, ao adotar critérios que incentivem o não cumprimento de uma das suas responsabilidades, que é a arrecadação dos tributos de sua competência, ou o aumento da despesa sem resultados a ela atrelados, como ocorre quando toda a distribuição da parcela discricionária é realizada por meio de critérios de distribuição tais quais a parte igualitária, área geográfica e população, assim como determinam as leis vigentes dos estados do Amazonas, Maranhão e Rio Grande do Norte, ou exclusivamente por meio da parte igualitária, empregado pelos estados de Roraima e Sergipe (parte 2 da Tabela 2). Em suma, as transferências não devem ser utilizadas para financiar práticas fiscais irresponsáveis.

A diretriz seguinte é o alcance. A alteração dos critérios para a distribuição da parcela discricionária gera ganhadores e perdedores. Portanto, deve-se analisar quem serão os ganhadores e os perdedores e o que isso representa para a política que se deseja incentivar. Um dos motivos para o sucesso da experiência do Ceará foi o maior número de ganhadores - municípios de pequeno porte - em detrimento do número de perdedores - municípios de grande porte. Além disso, o impacto nas receitas dos municípios perdedores tinha magnitude pequena, diferentemente do que ocorrera com os municípios ganhadores, em que, em alguns casos, a parcela discricionária passou a ser maior do que a não discricionária, cuja base de distribuição é o VAF. Ainda, a modificação da legislação ocorreu em um momento de estabilidade fiscal, com maior coerência entre as receitas e as despesas, e a implementação foi realizada no primeiro ano do mandato do prefeito eleito após a alteração da legislação. Todos esses fatores podem ter contribuído para suavizar a pressão dos municípios perdedores quanto às alterações da legislação.

Tem-se também a necessidade de previsibilidade. A análise dos ganhadores e perdedores pode ser favorecida pela disponibilidade de série histórica das variáveis relevantes do desenho de transferência, assim como a possibilidade de fazer projeções anuais/ mensais para um período de cinco anos ou mais. Logo, é possível avaliar o impacto das mudanças nos critérios e as exceções à regra, se aplicável ou não a todos os municípios, ou a utilização de algum mecanismo para compensar a redução das transferências da 
parcela discricionária da cota-parte do ICMS nos primeiros anos para os municípios perdedores, como, por exemplo, a realização de transferências voluntárias pelo estado.

A transparência é outra diretriz que deve ser considerada. A disseminação dos critérios, mesmo sua operacionalização, a capacitação dos municípios para se planejarem em relação à nova forma de transferência e os valores transferidos para todos os municípios, pode favorecer a avaliação por parte destes quanto aos objetivos e à adequação dos critérios de distribuição da parcela discricionária, bem como as possíveis modificações na legislação.

Para a alteração da legislação sobre a parcela discricionária, a simplicidade é uma diretriz que também deve ser analisada. A facilidade quanto ao entendimento dos critérios utilizados para distribuição da parcela discricionária é uma das características desejáveis, pois fórmulas muito complexas — em número e em relações entre as variáveis - podem dificultar o controle por parte dos municípios dos valores transferidos e favorecer aqueles que têm um quadro técnico mais capacitado para questionar o não atendimento de determinados critérios. Assim, a simplicidade pode evitar a desconfiança quanto às mudanças na legislação ao permitir identificar mais rapidamente quais serão os municípios ganhadores e os perdedores. O estado de Minas Gerais, por exemplo, apresenta 17 critérios de distribuição para a parcela discricionária, agrupados em dez categorias (parte 2 da Tabela 2). Entre eles, destina o percentual de $0,01 \%$ aos municípios mineradores. Isto é, sabem-se quais municípios seriam afetados negativamente com a eliminação desse critério, no entanto a quantidade elevada de critérios utilizados dificulta a análise de quais municípios ganhariam e/ou perderiam com uma possível alteração na legislação do ente. Situação similar ocorre com o estado do Amapá, pois a legislação vigente desse ente define a distribuição por meio de dez critérios de distribuição, agrupados em nove categorias (parte 2 da Tabela 2).

A distribuição da parcela discricionária com o intuito de resolver problemas em diferentes áreas/funções de governo pode acabar não tendo o impacto desejado em decorrência da pulverização do percentual a ser destinado para cada uma delas, ou ter o impacto concentrado em um número pequeno de municípios que apresentam certa característica que favoreça o recebimento das transferências, a qual se refere à focalização no desenho da transferência. Portanto, a mudança da legislação com o propósito de favorecer um regime de colaboração no ensino fundamental por meio da inserção de condicionalidades baseadas em outputs deve ocorrer não apenas pela inserção do critério relativo à educação, mas também pelo percentual destinado a esse critério,já que os valores a serem recebidos devem ser suficientemente relevantes para propiciar mudanças no comportamento do gestor municipal. Ademais, como visto pelo critério da simplicidade, quanto mais pulverizado o percentual de $25 \%$ da parcela discricionária, maior a dificuldade em identificar os municípios ganhadores e perdedores. Além disso, considerando que o critério relativo à educação do Ceará também contribui para a redistribuição das transferências para municípios menores, critérios que têm função similar quanto à equidade podem favorecer a mudança na legislação.

A salvaguarda dos objetivos do transferidor é outra diretriz importante que deve ser considerada no desenho das transferências intergovernamentais. Os objetivos do transferidor são mais bem garantidos quando as condicionalidades são baseadas em outputs, e não em inputs, pois o estado nem sempre conhece as variáveis condicionantes 
para a promoção da educação de cada município e pode adotar condicionalidades baseadas em inputs que vão de encontro aos objetivos delineados. Além disso, as transferências baseadas em outputs possibilitam flexibilidade aos municípios para a utilização dos valores transferidos, o que pode gerar gastos mais eficientes e evitar pressões sobre os seus orçamentos para atendimento das condicionalidades.

Ao considerar a diretriz da viabilidade, faz-se necessário observar que a distribuição da parcela discricionária é uma das fontes de financiamento do ensino fundamental dos municípios e deve ser analisada juntamente com as demais fontes, como o Fundeb. Também, o critério deve ser congruente com o objetivo que se deseja alcançar, o que pode variar em cada estado, dada a diversidade de características socioeconômicas. Portanto, cabe a indagação se as transferências referentes à parcela discricionária teriam o mesmo impacto no comportamento dos gestores municipais de diferentes estados brasileiros, isso porque, entre outros fatores, a relevância dos valores transferidos aos orçamentos municipais pode variar de maneira significativa.

Adicionalmente, devem-se levar em conta o espaço no orçamento do estado para comportar compensações a municípios perdedores, ações a serem executadas pelo próprio estado (por exemplo, apoio técnico) e o desenvolvimento e implementação de um sistema de avaliação e monitoramento que possibilite as transferências baseadas em outputs. Em suma, a distribuição da parcela discricionária fundamentada em condicionalidades baseadas em outputs pode favorecer o alcance dos resultados desde que faça diferença nos orçamentos municipais e que o esforço seja direcionado para o alcance de metas delineadas em consonância com o Plano de Educação, que é mais amplo do que o critério em si.

Por fim, tem-se a accountability por resultados. $\mathrm{O}$ desenho das transferências da parcela discricionária pautado em condicionalidades baseadas em outputs pode promover a accountability dos gestores municipais, do gestor estadual e dos resultados alcançados no ensino fundamental.

\section{CONSIDERAÇÕES FINAIS}

É possível constatar que há diretrizes que devem ser consideradas para o desenho das transferências que dependem mais fortemente das leis estaduais que determinam os critérios de distribuição da parcela discricionária. No entanto, há outras diretrizes que devem ser pensadas em um contexto mais geral, como no Plano de Educação, que prevê o regime de colaboração.

Das 15 diretrizes abordadas, nove devem ser compreendidas em um contexto mais amplo do que as leis estaduais: clareza dos objetivos, adequação da receita, capacidade de resposta, eficiência, alcance, previsibilidade, transparência, viabilidade e accountability por resultados.

Por outro lado, as seis diretrizes que dependem fortemente das leis estaduais são: autonomia, equidade, incentivo, simplicidade, focalização e salvaguarda dos objetivos do transferidor. Assim, para a alteração da legislação com vistas a alcançar o objetivo proposto - favorecer um regime de colaboração no ensino fundamental por meio da inserção de condicionalidades baseadas em outputs -, é indispensável analisar as particularidades de cada ente estadual. Pela análise das leis 
estaduais de Minas Gerais e Amapá, por exemplo, considerando-se as diretrizes simplicidade e focalização, seria possível afirmar que a alteração da legislação em tais entes seria mais difícil de ser operacionalizada, pois ambos os estados possuem quantidade elevada de critérios de distribuição - 17 e 10, respectivamente -, e há pulverização do percentual concernente à parcela discricionária, cujos critérios de distribuição referentes à educação destinam percentuais que se limitam a $2 \mathrm{e}$ $2,6 \%$, respectivamente.

Além disso, para as leis classificadas como tradicionais (Quadro 3), constata-se que a alteração das leis, seja para quase tradicional, seja para não tradicional, pode reduzir a autonomia dos governos municipais, uma vez que se atribuiriam condicionalidades às transferências e, portanto, a independência e a flexibilidade dos governos seriam reduzidas. Assim, levando-se em conta tal diretriz, os estados do Amazonas, Maranhão, Rio Grande do Norte, Santa Catarina, Roraima e Sergipe seriam mais desfavoráveis às alterações dos seus critérios de distribuição, haja vista que suas leis se classificam como tradicionais.

Em suma, as diretrizes abordadas por Shah (2007) aplicadas ao desenho da transferência da parcela discricionária com vistas ao favorecimento de um regime de colaboração no ensino fundamental devem ser consideradas para verificar quais entes são mais ou menos propensos a alterarem suas leis.

\section{REFERÊNCIAS}

ABRUCIO, F. L.; FRANZESE, C.; SANO, H. Coordenação e cooperação no federalismo brasileiro: avanços e desafios. In: CUNHA, A. S.; MEDEIROS, B. A.; AQUINO, L. C. (org.). Estado, instituições e democracia: república. Brasília: Ipea, 2010. v. 1. Disponível em: https://www.ipea.gov.br/portal/index.php?option=com content\&view=article\&id=6533. Acesso em: 15 maio 2020.

ABRUCIO, F. L.; SEGGATTO, C. I. O manifesto dos pioneiros e o federalismo brasileiro: percalços e avanços rumo a um sistema nacional de educação. In: CUNHA, C. et al. (org.). O sistema nacional de educação: diversos olhares 80 anos após o Manifesto. Brasília: Ministério da Educação, 2014. p. 44-61.

ABRUCIO, F. L.; SEGGATTO, C. I.; PEREIRA, M. C. G. Regime de colaboração no Ceará: funcionamento, causas do sucesso e alternativas de disseminação do modelo. São Paulo: Instituto Natura, 2016. Disponível em: http://www.institutonatura.org.br/ wp-content/uploads/2016/12/Relatorio-Ceara-AF-Web.pdf. Acesso em: 15 maio 2020. ALBUQUERQUE, M.T. P. R. Uma análise da cota-parte do ICMS dos municípios cearenses. 2009. 98f. Dissertação (Mestrado Profissional em Economia do Setor Público) - Universidade Federal do Ceará, Fortaleza, 2009. Disponível em: http://www. repositorio.ufc.br/handle/riufc/6143. Acesso em: 15 maio 2020.

BARROS, F. M. Inovação no federalismo para o desenvolvimento e a cidadania: perspectivas de modelagem das transferências intergovernamentais de recursos. 2001. 250f. Dissertação (Mestrado em Administração Pública e Governo) - Fundação Getúlio Vargas, São Paulo, 2001. Disponível em: http://bibliotecadigital.fgv.br/dspace/ handle/10438/5322. Acesso em: 15 maio 2020. 
BARROSO, C. C. Impacto da cota parte do ICMS sobre os resultados educacionais nos municípios cearenses. 2015. 35f. Dissertação (Mestrado em Economia) - Universidade Federal do Ceará, Fortaleza, 2015. Disponível em: http://repositorio.ufc.br/bitstream/riufc/15255/1/2015_dissert_ccbarroso.pdf. Acesso em: 15 maio 2020.

BRANDÃO, J. B. O rateio de ICMS por desempenho de municípios no Ceará e seu impacto em indicadores do sistema de avaliação da educação. 87f. Dissertação (Mestrado em Administração) - Fundação Getúlio Vargas, Rio de Janeiro, 2014. Disponível em: https://bibliotecadigital.fgv.br/dspace/handle/10438/13149. Acesso em: 15 maio 2020.

BRASIL. Constituição da República Federativa do Brasil de 1988. Brasil, 1988. Disponível em: http://www.planalto.gov.br/ccivil_03/constituicao/ ConstituicaoCompilado.htm. Acesso em: 15 maio 2020.

BRASIL. Emenda Constitucional no 14, de 12 setembro de 1996. Brasil, 1996a. Disponível em: http://www.planalto.gov.br/ccivil_03/constituicao/emendas/emc/ emc14.htm. Acesso em: 15 maio 2020.

BRASIL. Lei no 12.612, de 7 de agosto de 1996. Brasil, 1996b. Disponível em: http:// astal.com.br/legislacao/legi_ceara_lei12612.htm. Acesso em: 15 maio 2020.

BRASIL. Lei no 157, de 20 de janeiro de 2004. Brasil, 2004a. Disponível em: http:// app1.sefaz.mt.gov.br/0425762E005567C5/250A3B130089C1CC042572ED0051D0A1/7DEDB9DE180B3E9A04256E220072D052. Acesso em: 15 maio 2020.

BRASIL. Lei no 1.530, de 22 de janeiro de 2004. Brasil, 2004b. Disponível em: http:// www.al.ac.leg.br/leis/wp-content/uploads/2014/09/Lei1530.pdf. Acesso em: 15 maio 2020.

BRASIL. Emenda Constitucional no 53, de 19 dezembro de 2006. Brasil, 2006. Disponível em: http://www.planalto.gov.br/ccivil_03/constituicao/Emendas/Emc/ emc53.htm. Acesso em: 15 maio 2020.

BRASIL. Lei $\mathbf{n}^{\mathbf{0}} \mathbf{1 4 . 0 2 3}$, de 17 de dezembro de 2007. Brasil, 2007. Disponível em: https://www.legisweb.com.br/legislacao/?id=122702. Acesso em: 15 maio 2020.

BRASIL. Decreto no 29.306, de 05 de junho de 2008. Brasil, 2008. Disponível em: https://www.legisweb.com.br/legislacao/?id=122804. Acesso em: 15 maio 2020.

BRASIL. Decreto no 30.796, de 29 de dezembro de 2011. Brasil, 2011. Disponível em: https://www.jusbrasil.com.br/diarios/33399653/doece-caderno-1-29-12-2011-pg-8. Acesso em: 15 maio 2020.

BRASIL. Ministério da Educação. Instituir um Sistema Nacional de Educação: agenda obrigatória para o país. Brasil, 2015. Disponível em: http://pne.mec.gov.br/ images/pdf/SNE_junho_2015.pdf. Acesso em: 15 maio 2020.

CARNEIRO,D.;IRFFI,G.Avaliaçãocomparativadasleisdeincentivoà educaçãonoCeará. Fortaleza:UFC,2017.Disponível em: https:/www.bnb.gov.br/documents/160445/2051679/ Avaliação+comparativa+das+Leis+de+Incentivo+à+Educação+no+Ceará.pdf/8157cc828592-9bbc-1367-0c8ffbdfbb82. Acesso em: 15 maio 2020.

FRANCA, E.M. Repasse da cota-parte do ICMS aos municípios cearenses: avaliação das mudanças ocorridas no período de 2009 a 2011. 2014. 77f. Dissertação (Mestrado 
Profissional em Economia do Setor Público) - Universidade Federal do Ceará, Fortaleza, 2014. Disponível em: http://www.repositorio.ufc.br/bitstream/riufc/15161/1/2014_ dissert_emfranca.pdf. Acesso em: 15 maio 2020.

GARCIA, F. G.; SIMONASSI, A. G.; COSTA, R. F. R. A Lei 14.023/07 e os investimentos em educação fundamental e saúde nos municípios cearenses: uma análise no período 2006-2010. Economia e Desenvolvimento, v. 14, n. 1, p. 3-24, 2015. Disponível em: http://periodicos.ufpb.br/index.php/economia/article/ view/27510/14792. Acesso em: 15 maio 2020.

LIMA,A.E. M. O efeito do desempenho educacional sobre o repasse da cota parte do ICMS para os municípios cearenses. 2012. 42f. Dissertação (Mestrado em Economia) Universidade Federal do Ceará, Fortaleza, 2012. Disponível em: http://www.repositorio. ufc.br/bitstream/riufc/6308/1/2012_dissert_aemlima.pdf. Acesso em: 15 maio 2020.

MENDES, M. Federalismo fiscal. In: ARVANTE, P. R.; BIDERMAN, C. (org.). Economia do setor público. Rio de Janeiro: Campus/Elsevier, 2004. p. 421-461.

NOGUEIRA, C. A. G. Efeitos distributivos das políticas públicas: o caso da nova metodologia de cálculo da cota parte do ICMS do Ceará. Revista FSA, v. 9, n. 1, jan./ jul. 2012. Disponível em: http://www4.unifsa.com.br/revista/index.php/fsa/article/ view/24/19. Acesso em: 15 maio 2020.

PETTERINI, F. C.; IRFFI, G. D. Evaluating the impact of a change in the ICMS tax law in the state of Ceará in municipal education and health indicators. Economia, v. 14, n. 3-4, p. 171-184, 2013. Disponível em: https://econpapers.repec.org/article/ anpeconom/v_3a14_3ay_3a2013_3ai_3a2_3a171_5f184.htm. Acesso em: 15 maio 2020.

SALES, P. S. T. Avaliação da distribuição das cotas-parte do ICMS devidas aos municípios cearenses: cenários alternativos. $72 \mathrm{f}$. Dissertação (Mestrado em Economia) - Universidade Federal do Ceará, Fortaleza, 2011. Disponível em: http:// www.repositorio.ufc.br/bitstream/riufc/5768/1/2011_dissert_pstsales.pdf. Acesso em: 15 maio 2020.

SECRETARIA DE ESTADO DA FAZENDA DA PARAÍBA. Lei no 9.600 de 21 de dezembro de 2011. 2011. Disponível em: https://www.sefaz.pb.gov.br/legislacao/64leis/icms/614-lei-n-9-600-de-21-de-dezembro-de-2011. Acesso em: 28 set. 2021.

SHAH,A.A practitioner's guide to intergovernamental fiscal transfers. In: BOADWAY, R.; SHAH,A. (org.).Intergovernmental fiscal transfers: principles and practice. Washington, D.C.:The World Bank, 2007.p.1-53. Disponível em: https://openknowledge.worldbank. org/bitstream/handle/10986/7171/380770Fiscal0t101OFFICIAL0USE0ONLY1. pdf? sequence=1\&isAllowed=y. Acesso em: 15 maio 2020.

\section{SOBRE AS AUTORAS}

Maiara Sasso é doutoranda em controladoria e contabilidade pela Universidade de São Paulo (USP). Professora da Fundação Instituto de Pesquisas Contábeis, Atuariais e Financeiras (FIPECAFI).

E-mail:maiarasassop@gmail.com 
Patrícia Siqueira Varela é doutora em controladoria e contabilidade pela Universidade de São Paulo (USP). Professora da mesma instituição.

E-mail: psvarela@usp.br

Patricia Righetto é mestra em gestão de políticas públicas pela Universidade de São Paulo (USP).

E-mail: patricia.righetto@usp.br

Conflitos de interesse: As autoras declaram que não possuem nenhum interesse comercial ou associativo que represente conflito de interesses em relação ao manuscrito.

Financiamento: $\mathrm{O}$ presente estudo foi encomendado e financiado pelo Instituto Natura (São Paulo), mas revela a análise e as reflexões das pesquisadoras, e não do Instituto Natura.

Contribuições das autoras: Análise formal, Conceituação, Curadoria de dados, Investigação, Metodologia: Sasso, M.; Varela, P.S.; Righetto, P. Administração do projeto, Escrita - revisão e edição, Supervisão, Validação, Visualização: Sasso, M.; Varela, P.S. Escrita - primeira redação: Sasso, M. Obtenção de financiamento: Varela, P.S.

Recebido em 26 de junho de 2020 Aprovado em 22 de fevereiro de 2021 